\title{
Cutaneous Calcinosis in Limited Cutaneous Systemic Scleroderma: Clinical Case and Review of
} Therapeutic Options

\author{
Kaba Conde ${ }^{1,2}$, Kadidjatou Igue ${ }^{2,}$, Mohamed Awada ${ }^{1}$, Carlos Othon Guelngar ${ }^{2}$, Mamadou Hady Diallo ${ }^{2}$, Male Dore ${ }^{2}$ \\ ${ }^{1}$ Rheumatology Department, Ignace Deen National Hospital, Conakry University Hospital, CHU Conakry \\ ${ }^{2}$ Neurology Department, Ignace Deen National Hospital, CHU Conakry \\ *Corresponding Author: Kadidjatou Igue, Neurology Department, Ignace Deen National Hospital, CHU Conakry
}

Received date: 12 January 2021; Accepted date: 03 February 2021; Published date: 08 February 2021

Citation: Conde K, Igue K, Awada M, Guelngar CO, Diallo MH, et al. Cutaneous Calcinosis in Limited Cutaneous Systemic Scleroderma: Clinical Case and Review of Therapeutic Options. J Med Case Rep Case Series 2(2): https://doi.org/10.38207/jmcrcs20210004

Copyright: (C) 2021 Igue K. This is an open-access article distributed under the terms of the Creative Commons Attribution License, which permits unrestricted use, distribution, and reproduction in any medium, provided the original author and source are credited.

\begin{abstract}
We report the case of a 68-year-old patient of Moroccan origin is known for limited systemic cutaneous scleroderma since 2012. The diagnosis of systemic scleroderma was selected in accordance with the ACR/EULAR 2013 criteria. In August 2018, she came in consultation for diffuse calcinosis presenting as a subcutaneous nodule in pressure areas such as elbows, knees, and also in the hands associated with pain and swelling. X-rays of the elbows, hands, forearms, and knees showed voluminous bilateral calcifications. The patient was treated with calcium channel blockers, colchicine, and then bisphosphonates with no effect on calcinosis.
\end{abstract}

Keywords: limited cutaneous systemic scleroderma, calcinosis, guinea

\section{Introduction}

Calcinosis is the deposition of calcium hydroxyapatite in the skin and subcutaneous tissues [1, 2]. There are five subtypes of calcinosis: dystrophic, metastatic, iatrogenic, idiopathic, and calciphylaxis [3]. Dystrophic calcinosis is the subtype associated with autoimmune connective tissue diseases [2], such as systemic scleroderma (SSc) [4]. It is estimated that calcinosis is present in $40 \%$ of patients with limited

\section{Case Report}

The objective of this article is to present the case of a 68-year-old patient and to review the different treatment options. 68-year-old patient of Moroccan origin, with a history of colon neoplasia, known for limited systemic cutaneous scleroderma since 2012. The diagnosis of systemic scleroderma was retained in accordance with the ACR/EULAR 2013 criteria: skin thickening of the fingers (4 points), telangiectasia (2 points), capillaroscopic abnormalities (2 points), Raynaud's phenomenon (3 points), positive antinuclear antibodies: 1/1280 (centromere type: 3 points). She was treated with calcium channel blockers. In August 2018, she presented in consultation for diffuse calcinosis in the form of a subcutaneous nodule, in pressure areas such as the elbows (1B and C), knees (1D) but also in the hands (Figure 1 A), associated with pain and swelling (Figure 1). There was scleroderma [5]. It occurs in all subsets of scleroderma but is more common in patients with scleroderma with positive anticentromere antibodies [6]. Calcinosis is frequent and difficult to manage complication in patients with SSc. There are few treatment options and no known effective treatment to date [7].

also Raynaud's phenomenon and telangiectasia on the face. The cardiopulmonary and digestive examination was normal. Rodnan's score was 15/51. The biological assessment showed a normal blood count, no inflammatory syndrome (VS, normal CRP). Kidney and liver function were normal. The phosphocalcic balance was normal. Immunological workup showed $1 / 1280$ positive anti-nuclear antibodies, positive anti-centromere antibodies. While anti-dsDNA, anti-ENA, rheumatoid factors, and anti-CCP antibodies were negative. $\mathrm{X}$-rays of the elbows, hands, forearms, and knees showed voluminous bilateral calcifications (Figure 2). Chest X-ray was normal. Thus, the diagnosis of localized cutaneous SSc associated with calcinosis. Treatment with colchicine and then bisphosphonates was started. 


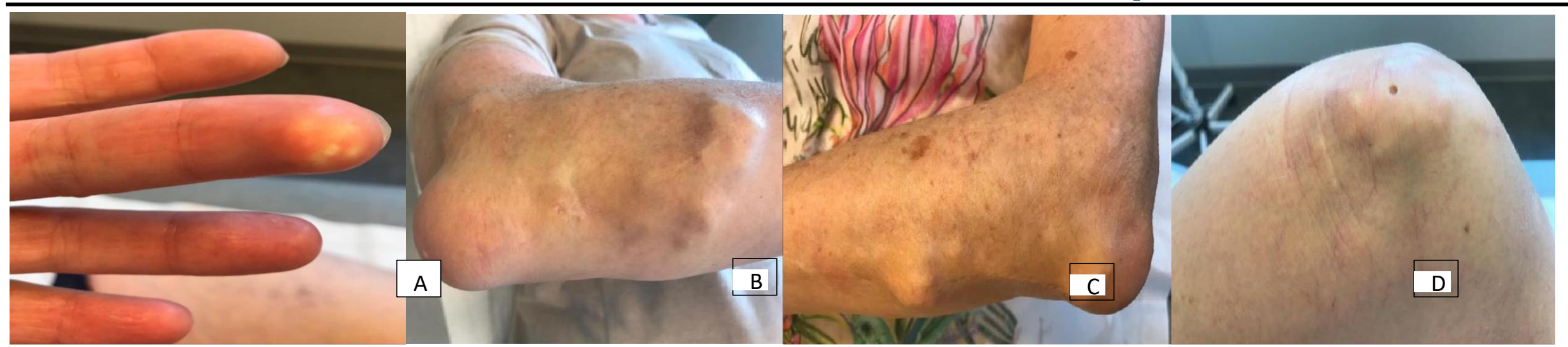

Figure 1. Photograph of the left fingers (A), the forearms and elbows (B, C) and the right knee (D) showing the presence of calcinosis and calcinotic nodule.
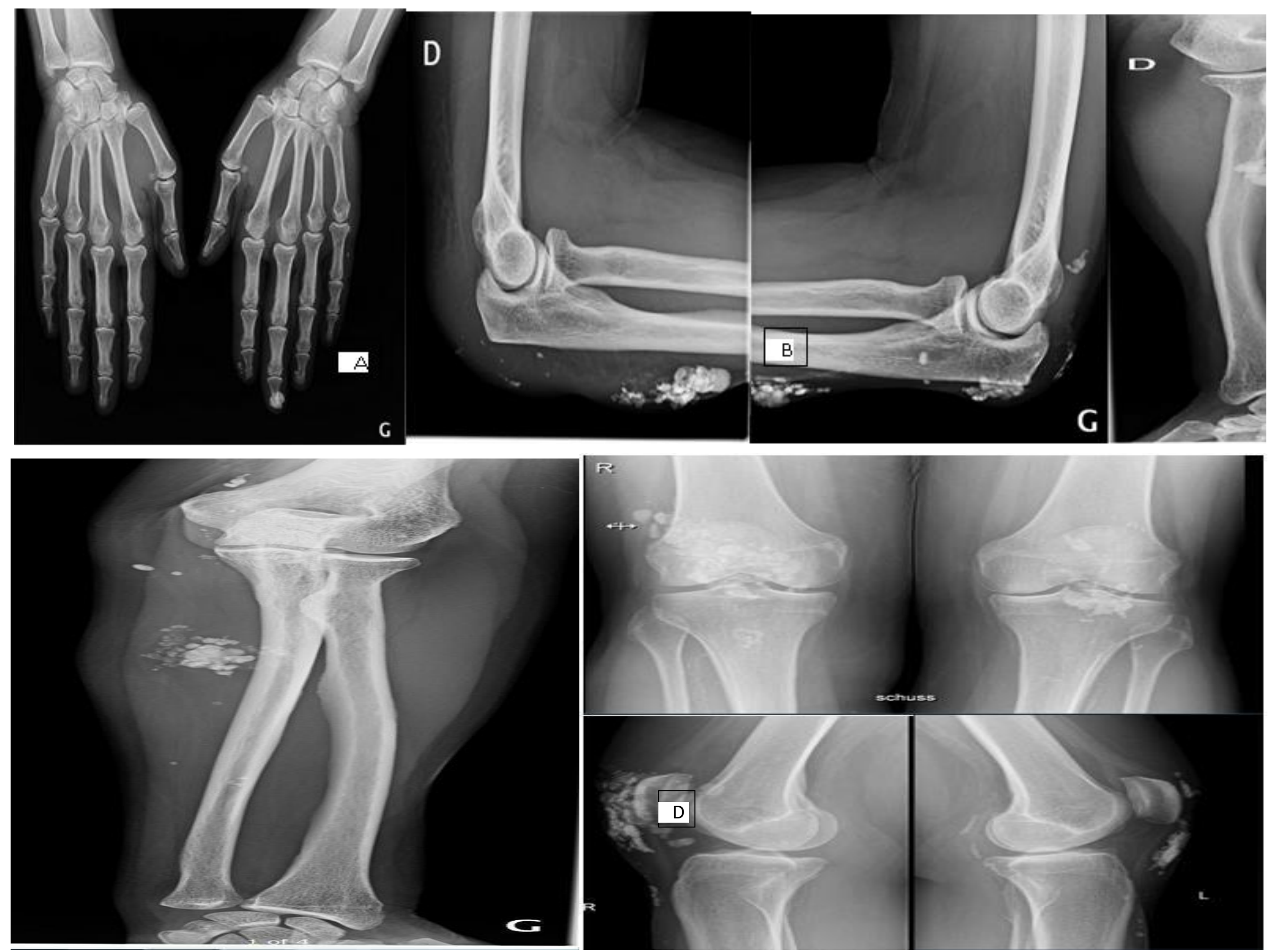

Figure 2. X-ray of the hands, forearms and knees showing the presence of large calcification.

\section{Discussion}

Calcinosis is the deposition of calcium hydroxyapatite in the skin and subcutaneous tissues [1,2]. The prevalence of calcinosis in patients with SSc is in the range of $20 \%$ to $40 \%$ [5]. Although calcinosis is frequently encountered in patients with localized cutaneous SSc, formerly known as CREST syndrome (Calcinosis, Raynaud's phenomenon, esophageal involvement, sclerodactyly, and telangiectasia), it also occurs in forms with diffuse cutaneous involvement [6]. The pathogenesis of calcinosis associated with SSc is unknown and there is currently no treatment with proven efficacy [8, 9]. General measures include improving blood flow to the extremities by avoiding trauma, stress, and exposure to cold. Antibiotic therapy covering streptococci and staphylococci if there is a suspicion of superinfection of calcinotic lesions [10]. Paracetamol, non-steroidal anti-inflammatory drugs, and opioids for pain relief [11]. Many treatment options have been tried over the years, but none have been accepted as standard treatment $[2,7]$. 


\section{Calcium channel blockers}

Several studies have shown an effect of calcium inhibitors (CI) on the intracellular calcium concentration in calcinotic tissues. Diltiazem is the most widely used CI to treat calcinosis in SC at a dose of 240-480 $\mathrm{mg} /$ day with controversial efficacy $[12,13,14]$. In a retrospective study of patients with connective tissue disease and calcinosis, nine

\section{Bisphosphonates}

Bisphosphonates may be useful in reversing the calcification process by inhibiting the macrophages responsible for the production of proinflammatory cytokines and the reduction of bone resorption [15]. Brief reports describe an improvement in calcinosis after treatment

\section{Sodium thiosulfate}

Sodium thiosulfate (STS) topical, intralesional and intravenous has been studied as a treatment for calcinosis [17]. Goossens et al. reported two cases of weekly intralesional injections of 1 to $3 \mathrm{~g}$ of STS with pain relief, functional improvement, and a $59 \%$ reduction in height after 12 months [18]. A larger series describes the treatment of eight lesions in six patients (five with STS and one with nephrogenic systemic fibrosis) with injections of 12.5 to $275 \mathrm{mg}$ STS

\section{Colchicine}

Several studies recommend colchicine as a first-line treatment [20] although there is very little evidence. In the Mayo Clinic, a retrospective series of 78 patients with calcinosis (including 24 with $\mathrm{SSc}$ [21], the only patient to receive a complete response to medical

\section{Biotherapies}

Rituximab is the most widely used biological agent in the treatment of calcinosis (RTX). One case report showed complete resolution with RTX administered in four weekly infusions $\left(375 \mathrm{mg} / \mathrm{m}^{2}\right)$ [22]. However, other studies have shown a progression of calcinosis 6 to 12 months after stopping RTX. Activated macrophages appear to play a role in the pathophysiology of calcinosis and TNF alpha has been shown to be present in calcinosis. Consequently, infliximab has been tried effectively in a series of five patients with myositis and one with overlapping syndrome [23].

\section{Conclusion}

Calcinosis is a frequent and difficult to manage complication in patients with systemic scleroderma. Many treatment options have been out of seventeen patients who received diltiazem $(\leq 480 \mathrm{mg} /$ day $)$ had a partial response to calcinosis [13]. However, in another series of twelve scleroderma patients treated with diltiazem $180 \mathrm{mg} / \mathrm{d}$, only three had discrete radiographic improvement [14].

with pamidronate, alendronate, and risedronate. However, given the paucity of evidence, the efficacy of bisphosphonates in the treatment of calcinosis remains uncertain [16].

$150 \mathrm{mg} / \mathrm{ml}$ for up to 4 weeks. At weeks 4 and 12, lesion size decreased by $67 \%$ and $90 \%$, respectively, and all patients reported improvement in pain and disability [19]. Several studies have demonstrated the efficacy of STS in the treatment of calcinosis however, controlled trials are needed before sodium thiosulfate (either IV or topical) can be recommended as a standard treatment for calcinosis $[\mathbf{1 6 , 1 7 ]}$.

treatment was one of eight patients treated with colchicine. Since areas of calcinosis can cause "flare-ups", probably due to loss of crystals in the soft tissues, this approach may be justified.

IV Ig is an immunomodulatory treatment and has been tried in a few cases of calcinosis with conflicting results. In the positive Schanz's study, the authors postulated that the improvement in calcinosis was due to an anti-inflammatory effect of IV Ig, possibly by inhibition of macrophage function [24]. Other treatments such as warfarin, minocycline, ceftriaxone, aluminum hydroxide, and triamcinolone in the treatment of SSc calcinosis with controversial results $[\mathbf{2 5}, \mathbf{2 6}]$. Extracorporeal lithotripsy improves the pain and size of calcinosis. Surgery is reserved for severe and refractory calcinosis.

tried over the years, but none have been accepted as standard treatment Only sodium thiosulfate has shown some efficacy.

Conflicts of interest: The authors declare that they have no conflicts of interest. 


\section{References}

1. Chander S, Gordon P (2012) Soft tissue, and subcutaneous calcification in connective tissue diseases. Curr Opin Rheumatol 24(2): 158-164.

2. Valenzuela A, Song P, Chung L (2018) Calcinosis in scleroderma. Curr Opin Rheumatol. 30(6): 554-561.

3. Boulman N, Slobodin G, Rozenbaum M, Rosner I (2005) Calcinosis in rheumatic diseases. Semin Arthritis Rheum 34(6): 805-812.

4. Gutierrez A Jr, Wetter DA (2012) Calcinosis cutis in autoimmune connective tissue diseases. Dermatol Ther 25(2): 195-206.

5. Hsu VM, Emge T, Schlesinger N (2017) X-ray diffraction analysis of spontaneously draining calcinosis in scleroderma patients. Scand J Rheumatol. 46(2): 118-121.

6. Duzgun N (2017) Cutaneous calcinosis in a patient with limited scleroderma: CREST Syndrome. Eur J Rheumatol. 4(4): 305 306.

7. Herrick AL, Gallas A (2016) Systemic-sclerosis-related calcinosis. J Scleroderma Relat Disord 1(2): 194-203.

8. Valenzuela A, Chung L (2015) Calcinosis: pathophysiology and management. Curr Opin Rheumatol. 27(6): 542-548.

9. Pai S, Hsu V (2018) Are there risk factors for sclerodermarelated calcinosis? Mod Rheumatol. 28(3):518-522.

10. Ughi N, Crotti C, Ingegnoli F (2016) Effectiveness, and safety of oxycodone/naloxone in the management of chronic pain in patients with systemic sclerosis with recurrent digital ulcers: two case reports. Clin Interv Aging 11(1): 307-311.

11. Netsch D (2018) Calcinosis cutis: WOC nurse management. J Wound Ostomy Continence Nurs 45(1): 83-86.

12. Palmieri GM, Sebes JI, Aelion JA, Moinuddin M, Ray MW et al. (1995) Treatment of calcinosis with diltiazem. Arthritis Rheum 38(11): 1646-1654.

13. Dolan AL, Kassimos D, Gibson T, Kingsley GH (1995) Diltiazem induces remission of calcinosis in scleroderma. $\mathrm{Br} \mathrm{J}$ Rheumatol 34(6): 576-578.

14. Farah MJ, Palmieri GM, Sebes JI, Cremer MA, Massie JD et al. The effect of diltiazem on calcinosis in a patient with the CREST syndrome. Arthritis Rheum 33(8): 1287-1293.
15. Fujii N, Hamano T, Isaka Y, Ito T, Imai E (2005) Risedronate: a possible treatment for extraosseous calcification. Clin Calcium 15(1): 75-78.

16. Bair B, Fivenson D (2011) A novel treatment for ulcerative calcinosis cutis. J Drugs Dermatol 10(9): 1042-1044.

17. Barrio-Diaz P, Moll-Manzur C, Alvarez-Veliz S, VeraKellet C (2016) Topical sodium metabisulfite for the treatment of calcinosis cutis: a promising new therapy. $\mathrm{Br} \mathrm{J}$ Dermatol. 175(3): 608-611.

18. Goossens J, Courbebaisse M, Caudron E, Bahans C, Vacquerie V et al. (2017) Efficacy of intralesional sodium thiosulfate injections for disabling tumoral calcinosis: two cases. Semin Arthritis Rheum 47(3): 451-455.

19. Baumgartner-Nielsen J, Olesen AB (2016) Treatment of skin calcifications with intralesional injection of sodium thiosulphate: a case series. Acta Derm Venereol 96(2): 257258.

20. Bienvenu B. Treatment of calcinoses of Connectivites. Rev Med Interne. 35(7): 444-452.

21. Sparsa A, Lesaux N, Kessler E, Bonnetblanc JM, Blaise S et al. (2005) Treatment of cutaneous calcinosis in CREST syndrome by extracorporeal shock wave lithotripsy. J Am Acad Dermatol. 53(5) (S1): S263-S265.

22. De Paula DR, Klem FB, Lorencetti PG, Muller C, Azevedo VF et al. (2013) Rituximab-induced regression of CRESTrelated calcinosis. Clin Rheumatol 32(2): 281-283.

23. Tosounidou S, MacDonald H, Situnayake D (2014) Successful treatment of calcinosis with infliximab in a patient with systemic sclerosis/myositis overlap syndrome. Rheumatology (Oxford) 53(5): 960-961.

24. Schanz S, Ulmer A, Fierlbeck G (2008) Response of dystrophic calcification to intravenous immunoglobulin. Arch Dermatol 144(5): 585-587.

25. Cukierman T, Elinav E, Korem M, Chajek-Shaul T (2004) Low dose warfarin treatment for calcinosis in patients with systemic sclerosis. Ann Rheum Dis 63(10): 1341-1343.

26. Lassoued K, Saiag P, Anglade MC, Roujeau JC, Touraine RL (1988) Failure of warfarin in treatment of calcinosis universalis. Am J Med 84(4): 795-796. 